\section{Physiology of exercise in orofacial motricity: knowledge about the issue}

\author{
Geciane Maria Xavier Torres ${ }^{1}$ \\ https://orcid.org/0000-0002-2686-5374 \\ Carla Patrícia Hernandez Alves Ribeiro César ${ }^{1}$ \\ https://orcid.org/0000-0002-9439-9352
}

Universidade Federal de Sergipe - UFS, Lagarto, Sergipe, Brasil.

Conflict of interests: Nonexistent

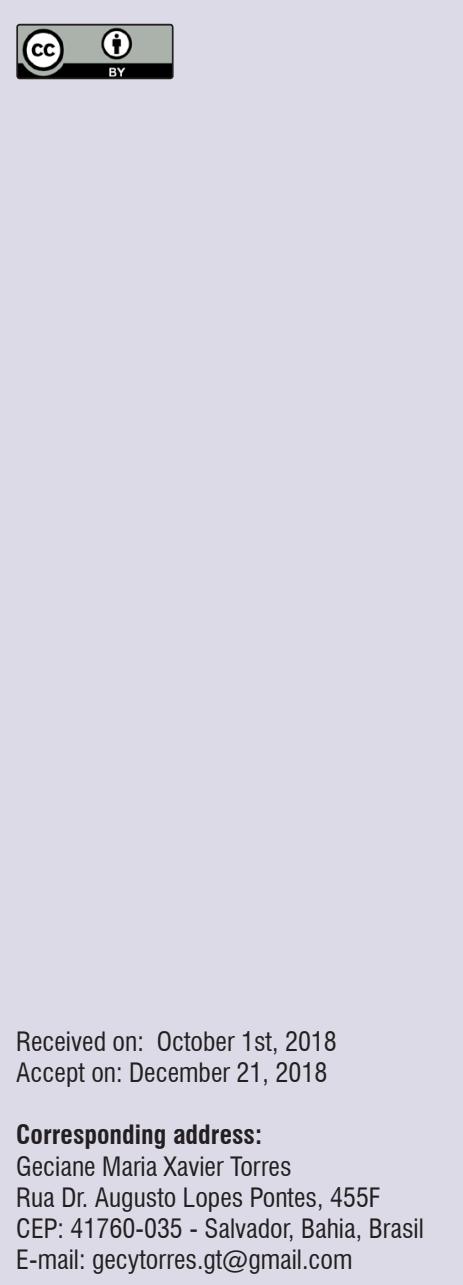

\section{ABSTRACT}

Objective: to investigate the knowledge of speech therapists about the physiology of exercise in orofacial motricity.

Methods: 38 speech therapists working in orofacial motricity in the state of Sergipe, Brazil, graduated from institutions of higher education in Brazil, answered eleven closed questions about the type of exercise, frequency, time of muscle contraction, serial number and signs and symptoms of muscular fatigue. The results were analyzed by the Kolmogorov-Smirnov and Chi-square tests (5\% significance).

Results: the variation of the exercises regarding the time of contraction was cited by the majority $(89.47 \%)$ and the serial number throughout therapy by all the participants. There was a $60.52 \%$ improvement on the isometric and isotonic exercises, $55.26 \%$ on the application of exercises in asymmetries and $47.34 \%$ on the sequence of exercises according to the type of muscular contraction. The majority of the participants conducted home exercises for more than three days a week (73.69\%), and .63\% participants indicated the interval time between one minute and two minutes. The most commonly reported signs and symptoms of muscle fatigue in the face were tremor / fibrillation (78.95\%).

Conclusion: the knowledge of the study group about the physiology of exercise still lacks greater technical-scientific subsidies.

Keywords: Exercise Therapy; Stomatognathic System; Professional Practice; Speech, Language and Hearing Sciences 


\section{INTRODUCTION}

Orofacial motricity, with the purpose of reestablishing the oral functions, appropriates two lines of reasoning: myotherapy and myofunctional therapy ${ }^{1}$. Myotherapy aims, through specific exercises, to modify muscular behavior, while myofunctional therapy works directly with the oral functions that are to be adapted, thus, aiming at muscle modification ${ }^{2}$.

These muscle modifications occur due to the characteristics of the skeletal muscle tissue, since it has a voluntary contraction and is fixed in the skeletal system. It is composed of muscle fascicles, that is, groups of muscle fibers composed of myofibrils and these, of myofilaments that slide between them during muscle contraction ${ }^{3}$. This contraction is activated by the nervous system ${ }^{4}$, which activate this contraction, and there are two types of contraction: the isotonic and the isometric, adapting to the fixation points of the muscle ${ }^{5}$.

The isotonic contraction occurs when one extremity of the muscle is fixed, and the other is movable, against a constant force, determining the diminution of the size of the muscle and consequent movement of the follow-up to which it is fixed. The isometric approach, however, occurs when the two muscular extremities are fixed, determining the increase of tension or force, without shortening the muscle or perceivable movement ${ }^{5}$.

The facial muscles, because they are skeletal striatum, are accustomed to these two types of contraction, but they differ from the others because they do not present facial sheaths, one of the characteristics of the skeletal muscles, and many of their fibers are inserted directly into the skin of the face ${ }^{6}$.

In addition to the anatomical orofacial and cervical knowledge, the speech therapist should also know about exercise physiology, which aims to study the acute and chronic effects of physical exercise on the structure and function of the various organ systems ${ }^{7}$. In order to explain the acute and chronic effects of exercise on cellular functions, in its fullness, exercise physiology needs to describe the responses observed as a result of exercise and physical training and explain the mechanisms involved. It is important to emphasize that the effects of exercises on different organic functions depend on the characteristics of those who execute them ${ }^{8}$.

In Orofacial Motricity, treatment is a process that involves the development of the patient's perception of what is altered; the preparation of skeletal facial muscles, usually performed with exercises; and guided corrective functional training. Therapeutic planning should take into account the particularities of the patient and be directed to the specific difficulties encountered'

When choosing myotherapy as a therapeutic line for the reestablishment of orofacial functions, the audiologist must know the reason for this choice. The exercise should not be the goal of therapy, but rather a tool that allows the patient to improve his perception and adjust his muscle tonus, if changed. Therefore, it is important that therapists, before thinking about the exercises that will be used, seek knowledge about the anatomy and physiology of all orofacial muscles ${ }^{1}$.

In the scientific literature, studies on muscle training in the face are scarce, and it is essential that the Speech, Language and Hearing Sciences researches that involve orofacial myofunctional exercises investigate the physiology of the exercises that are used in the therapeutic process ${ }^{1,2}$.

Therefore, this paper intends to investigate the knowledge of speech therapists about the physiology of exercise in orofacial motricity.

\section{METHODS}

Quantitative, descriptive and cross-sectional research, approved by the Research Ethics Committee of the Federal University of Sergipe under the No. 1.536.684 and CAAE No. 55208516.6.0000.5546.

For the composition of the sample, a sample calculation was made based on the number of speech therapists in the state of Sergipe $(n=304)$, according to the search conducted in September 2016, on the page of the Regional Speech, Language and Hearing Sciences Council (4th Region).

A margin of error of $20 \%$ and a confidence interval of $99 \%$ were used, obtaining the sample value of 38 subjects. Participants read and signed a Free and Informed Consent Form, in compliance with Resolution No 466 / 12 of the National Health Council, which was sent by e-mail.

Eligibility criteria were adopted for the inclusion of speech therapists working with Orofacial Motricity, attending patients with myofunctional orofacial dysfunction, in the state of Sergipe, without distinction regarding gender and age. The exclusion criteria were for those who worked in other areas of Speech, Language and Hearing Sciences, with titles stricto sensu and still working in the area of higher education in Orofacial Motricity. 
The collection of data occurred from the completion of an online form, specially developed for the accomplishment of the research.

For its elaboration, eleven questions were adapted from the questionnaire proposed in the literature ${ }^{10}$, containing questions of multiple choice, with content that included the type of exercise, frequency, time of muscle contraction, serial number and signs and symptoms of muscular fatigue. All questions were mandatory.

In order to verify whether or not the form met the objectives proposed for the research, two judges (SEZMB and CPHARC), with specialization in orofacial motricity for more than five years and professional performance for more than twenty years, analyzed the content of the collection instrument of data, verifying the representativeness of the items regarding concepts that were intended to be measured and, after adjustments and consensus, the collection instrument was applied to fifteen professional audiologists as a pilot phase - for testing the instrument. After this phase, the instrument was considered calibrated by judges and professionals, who were not included in the scope of the research sample. The final version of the data collection instrument is shown in Figure 1.

Questions three, four, five, seven, eight and eleven were scored with one point if the answer was correct. Questions six, nine, and ten were not scored. Thus, $100 \%$ accuracy corresponded to a total of six points.
For the composition of the sample, invitation was made by social network (Facebook) and by convenience (e-mail and telephone) to speech therapists in the state of Sergipe, where a link was made available to access the form (https://docs.google .com/forms/d/ e/1FAlpQLScmVtLaQyU3FthfEtr7xbKCIUzitupFSr13P2 qr9Zk2UW_ARA / viewform? usp = send_form), which was built in Google docs.

The results obtained were made available in an Excel spreadsheet (Microsoft ${ }^{\circledR}$ Office package) and analyzed by descriptive statistics, using a simple percentage, determining means and standard deviation. Afterwards, the data were tabulated and processed by the Statistical Package for Social Sciences (SPSS), version 21.0. The normality of the samples was observed by the Kolmogorov-Smirnov or the Shapiro-Wilk tests. The Kolmogorov-Smirnov or the Shapiro-Wilk tests observed the normality of the samples. In order to detect differences between groups of speech therapist professionals with or without specialization who work or not in the area of orofacial motricity, regarding the knowledge about the physiology of exercise in orofacial motricity, the Pearson's Chi-square test was used. The chi-square test was also used in the analyzes between the questionnaire responses for the entire sample. Alpha values were considered significant when lower than 0.05 . The established beta value was 0.1 . 
1. Do you attend patients with orofacial myofunctional dysfunction in your clinical practice? If the answer is no, you do not need to continue to respond to this form.

$\begin{array}{ll}0 & \text { Yes } \\ 0 & \text { No }\end{array}$

2. Do you have a specialization in Orofacial Motricity?
0 Yes
0 No

3. For which purpose you use the isotonic exercise in Orofacial Motricity?
0 To increase muscle tonus
0 To increase mobility

4. What is the purpose of isometric exercise in Orofacial Motricity?
$0 \quad$ To increase muscle strength
0 To increase mobility

5. When there is a need to work with isometric, isotonic and counter resistance exercises which sequence do you use?
$0 \quad$ Isotonic, Counter Resistance, Isometric
0 Isometric, Isotonic, Counter Resistance
$0 \quad$ Isotonic, Isometric, Counter Resistance
0 Counter Resistance, Isometric, Isotonic
0 Depends

6. Do you guide your patient to do home therapy exercises? How many days a week?

0 Two days a week

$0 \quad$ Three days a week

$0 \quad$ More than three days a week

$0 \quad$ I do not advise my patient to perform exercises at home

7. Do you think it necessary to vary the time of muscular contraction throughout the therapy?

$\begin{array}{ll}0 & \text { Yes } \\ 0 & \text { No } \\ 0 & \text { I don't know }\end{array}$

8. Do you think it necessary to vary the serial number throughout the therapy?
0 Yes
$0 \quad$ No
o I don't know

9. What interval time do you use from one set of exercises to another?

$0 \quad$ I do not use intervals between exercise series

$0 \quad$ Less than a minute

$0 \quad$ From one to two minutes

03 minutes or more

$0 \quad$ I don't know

10. What are the signs and symptoms indicative of muscle fatigue in the face region?
0 Pain
0 Tremor/fibrillation
$0 \quad$ Fatigue complaint
0 Compensatory movements
$0 \quad$ Noise in the temporomandibular joint
0 Increased articulatory imprecision in the act of speech

11. When there is asymmetry of tonus between the hemifaces, the indication of exercises should be:
$0 \quad$ With greater amount of series of exercises on the side with greater muscle tonus
$0 \quad$ With greater amount of series of exercises on the side with less muscle tonus
$0 \quad$ With an equal amount of series of exercises on the side between the hemifaces
0 I don't know

\section{Enviar}

Figure 1. Questionnaire adapted from Coutrin; Guedes; Motta ${ }^{11}$ applied in the study sample 


\section{RESULTS}

The female gender predominated in the study ( $89.47 \%$ of the sample), and the participants' ages ranged from 22 to 50 years, with a mean of 26.6 years old ( \pm 4.45$)$.

Of the forty-four respondents, six were excluded after applying the eligibility criteria, making up a sample with 38 speech therapists, of whom four (10.52\%) had specialization in OM. Although they work in Sergipe, Brazil, their formation (both undergraduate and specialization) occurred in different institutions of higher education in Brazil, not limited to the state itself.

Table 1 shows the results of the correct answers and errors recorded in the questions of the applied form.

Table 1. Right and Wrong answers of the 38 research participants in the questions of the data collection instrument

\begin{tabular}{lcccc}
\hline \multirow{2}{*}{ Content of the question } & \multicolumn{2}{c}{ Right Answers } & \multicolumn{2}{c}{ Wrong Answers } \\
\cline { 2 - 5 } & $\mathbf{N}$ & $\%$ & $\mathbf{N}$ & $\%$ \\
\hline Objectives of isotonic exercises & 23 & $60.52 \%$ & 15 & $39.48 \%$ \\
Objectives of isometric exercises & 23 & $60.52 \%$ & 15 & $39.48 \%$ \\
Sequence of exercises & 18 & $47.34 \%$ & 20 & $52.63 \%$ \\
Variation of muscle contraction time throughout therapy & 34 & $89.47 \%$ & 4 & $10.53 \%$ \\
Variation of serial number of exercises throughout therapy & 38 & $100 \%$ & 0 & $0 \%$ \\
Indication of exercises by asymmetry of muscle tonus & 21 & $55.26 \%$ & 17 & $44.74 \%$ \\
\hline
\end{tabular}

It should be emphasized that there was no statistically significant difference between the knowledge of specialists and non-specialists in OM regarding the use of different types of contraction: isometric or isotonic $(p=0.088)$, exercise sequence $(p=0.850)$, variation of the number of exercise sets (100\% accuracy), variation of muscle contraction time throughout the therapy $(p=0.60)$ and the exercises for asymmetry of muscle tonus in the hemifaces $(p=0.617)$.
Table 2 shows the results of the guidance provided by the speech therapist regarding the number of days in which the patient should perform the exercises at home. In this context, there was also no statistically significant difference between those with or without specialization in OM $(p=0.350)$.

Table 2. Speech therapist's orientation to the patient regarding the number of days in the week when one needs to perform orofacial myofunctional exercises at home

\begin{tabular}{lcc}
\hline Number of days suggested by speech therapist & N & $\%$ \\
\hline Two days a week & 0 & $0 \%$ \\
Three days a week & 7 & $18.42 \%$ \\
More than three days a week & 28 & $73.69 \%$ \\
I do not advise my patient to perform exercises at home & 3 & $7.89 \%$ \\
Total & 38 & $100 \%$ \\
\hline
\end{tabular}

Table 3 shows the results regarding the signs and symptoms considered by the research participants as indicative of muscular fatigue in the face region. There was no significant difference between the subjects with and without specialization when comparing the knowledge regarding signs of muscle fatigue in the exercises $(p=0.728)$. 
Table 3. Signs and symptoms of muscular fatigue in the face

\begin{tabular}{lcc}
\hline Signs and symptoms & N & $\%$ \\
\hline Pain & 18 & $47.37 \%$ \\
Tremor/fibrillation & 30 & $78.95 \%$ \\
Fatigue complaint & 19 & $50 \%$ \\
Compensatory Movements & 19 & $50 \%$ \\
Noise in the temporomandibular joint & 1 & $2.63 \%$ \\
Increased articulatory imprecision in the act of speech & 5 & $13.16 \%$ \\
\hline
\end{tabular}

Regarding the interval time, between the sets of exercises, used by the speech therapists who composed the sample, it can be verified that fifteen professionals (39.47\%) use less than one minute, twenty (52.63\%) use between one and two minutes and the minority ( $n=3 ; 7.90 \%$ ) use a time equal to or greater than three minutes. There was no significant difference between the subjects with and without specialization when comparing the knowledge regarding the variation of the interval time between the muscle contraction exercises during it $(p=0.77)$.

Table 4 allows visualizing the sum of points of the participants, with the mean and standard deviation of the group investigated.

Table 4. Sum of points per question, mean and standard deviation, of the 38 survey participants

\begin{tabular}{cccccccc}
\hline Subject No & Question 3 & Question $\mathbf{4}$ & Question $\mathbf{5}$ & Question $\mathbf{7}$ & Question $\mathbf{8}$ & Question $\mathbf{1 1}$ & Total \\
\hline 1 & 0 & 0 & 0 & 1 & 1 & 0 & 2 \\
2 & 0 & 0 & 1 & 1 & 1 & 0 & 3 \\
3 & 0 & 0 & 0 & 0 & 1 & 0 & 1 \\
4 & 1 & 1 & 1 & 1 & 1 & 0 & 5 \\
5 & 1 & 1 & 1 & 1 & 1 & 1 & 6 \\
6 & 0 & 0 & 0 & 1 & 1 & 0 & 2 \\
7 & 1 & 1 & 0 & 1 & 1 & 0 & 4 \\
8 & 0 & 0 & 0 & 1 & 1 & 0 & 2 \\
9 & 0 & 0 & 0 & 0 & 1 & 1 & 2 \\
10 & 0 & 0 & 1 & 1 & 1 & 0 & 3 \\
11 & 1 & 1 & 0 & 1 & 1 & 0 & 4 \\
12 & 1 & 0 & 0 & 1 & 1 & 0 & 3 \\
13 & 1 & 1 & 1 & 1 & 1 & 0 & 5 \\
14 & 1 & 1 & 1 & 1 & 1 & 1 & 6 \\
15 & 1 & 1 & 0 & 1 & 1 & 1 & 5 \\
16 & 0 & 0 & 0 & 1 & 1 & 0 & 2 \\
17 & 1 & 1 & 1 & 1 & 1 & 1 & 6 \\
18 & 1 & 1 & 1 & 1 & 1 & 0 & 5 \\
19 & 1 & 1 & 1 & 1 & 1 & 0 & 5 \\
20 & 1 & 1 & 1 & 1 & 1 & 1 & 6 \\
21 & 1 & 1 & 0 & 1 & 1 & 1 & 5 \\
22 & 1 & 1 & 1 & 1 & 1 & 1 & 6 \\
23 & 1 & 1 & 1 & 1 & 1 & 1 & 6 \\
24 & 1 & 1 & 1 & 0 & 1 & 1 & 5 \\
25 & 1 & 1 & 1 & 1 & 1 & 0 & 5 \\
26 & 0 & 0 & 1 & 1 & 1 & 1 & 4 \\
27 & 0 & 0 & 1 & 1 & 1 & 1 & 4 \\
28 & 0 & 0 & 0 & 1 & 1 & 1 & 3 \\
29 & 0 & 0 & 0 & 1 & 1 & & 1 \\
\hline
\end{tabular}




\begin{tabular}{cccccccc}
\hline Subject No & Question 3 & Question 4 & Question 5 & Question 7 & Question 8 & Question 11 & Total \\
\hline 30 & 1 & 1 & 0 & 1 & 1 & 0 & 4 \\
31 & 1 & 1 & 0 & 1 & 1 & 1 & 5 \\
32 & 0 & 0 & 0 & 1 & 1 & 1 & 3 \\
33 & 0 & 0 & 0 & 1 & 1 & 1 & 3 \\
34 & 0 & 0 & 0 & 1 & 1 & 1 & 3 \\
35 & 1 & 1 & 1 & 1 & 1 & 1 & 6 \\
36 & 1 & 1 & 0 & 1 & 1 & 1 & 5 \\
37 & 1 & 1 & 0 & 1 & 1 & 1 & 5 \\
38 & 1 & 1 & 1 & 1 & 1 & 0 & 5 \\
Total & 23 & 22 & 18 & 35 & 38 & 21 & 157 \\
\hline$\%$ & $60.52 \%$ & $57.89 \%$ & $47.37 \%$ & $92.10 \%$ \\
\hline \multicolumn{7}{c}{ Sight Answers mean = 4.13 } \\
\hline \multicolumn{7}{c}{}
\end{tabular}

Subtitle: SD = standard deviation.

\section{DISCUSSION}

The therapeutic process in Orofacial Motricity involves the preparation of the muscles, the development of the perception of what is altered and the directed corrective functional training ${ }^{9}$. The effectiveness of any training program encompasses the correct application of scientific principles in its organization, which depends on good control of variables such as intensity, volume, recovery interval, and training frequency ${ }^{11}$.

When analyzing the data referring to the knowledge of speech therapists about the exercises used in clinical practice and their sequence of application, it was verified that there is little applicability of the physiological parameters in the choice of these exercises. When questioned about what is the objective of the use of isotonic and isometric exercises, $39.47 \%$ of the participants reversed the objectives of these exercises. The literature ${ }^{1,7,11}$ commented that isotonic contraction exercises aim to improve muscle mobility and are indicated to increase the oxygenation and amplitude of the movements. Isometrics, however, aim to increase muscle strength and counter-resistance exercises and they cause more intense work on motor unit activation, increasing muscle strength and mobility.

It is known that when it is necessary to do all three types of exercises, it is interesting to start with the isotonic for the gain of mobility, followed by isometric aiming at the improvement of the muscle tonus and, finally, the exercise of resistance ${ }^{1}$. In the present study, the majority of the participants answered in disagreement with the literature on the use of the exercise sequence, evidencing the need for greater knowledge of this clinical premise in Orofacial Motricity.

When questioned about variation in contraction time, most speech therapists (89.18\%) found it necessary to vary the contraction time over the course of / throughout, in, for therapy. Literature shows that the degree of contraction depends on the number of motor units activated within the muscle. Moreover, generally, submaximal tensions are produced, since not all the muscle is activated during the requested activity ${ }^{6}$. Maximum voluntary contraction generates a maximum force defined as the highest force that the neuromuscular system can perform ${ }^{12}$. This maximum force will be bigger if the contraction time is greater or if higher velocity application is involved in a shorter time ${ }^{13}$. The most prevalent behavior in functional training is to vary the contraction time in a progressive, in order not to generate overtraining ${ }^{14}$, indicating that the research participants follow this condition in their professional practice.

In the present study, it was observed that all participants revealed that it is necessary to vary the number of series during the therapy. When analyzing the ability to maintain repeated actions at moderate or high intensity, it is necessary to measure the number of times it is possible to repeat an effort before the interruption by fatigue or to monitor the difficulty in maintaining the quality of the repetition. The ability to correctly repeat the movement compromises the total number of repetitions per set. It is recommended to consider, until the last repetition, the same mechanical characteristics of the first execution, except in very specific situations (muscle hypertrophy work). In practice, the work 
up to "failure to move" is usually applied in sports training ${ }^{11}$, and it is important that the speech therapist is aware of this aspect in order to avoid the condition of muscular fatigue. In addition, some neurological clinical conditions with an impact on oral functions (such as myasthenia gravis) deserve increased attention, since muscle fatigue can worsen the patient's clinical condition.

It is important, thus, to emphasize that the facial muscles are skeletal muscles, but they differ in some aspects, such as the absence of muscle spindles, small motor units, greater proximity and small size of the muscles, making isolated contraction more difficult. Therefore, it is necessary to consider these particularities when planning a program of facial muscle training ${ }^{14}$.

Among the participants, the minority stated that they did not guide the exercise at home. As for the frequency of training in number of days per week, most participating speech therapists advise the performance of the exercises for more than three days a week. Although there is still no standardization in speech therapy for parameters, such as series frequency and number of days in the week for the performance of myofunctional exercises, some studies used the methodology to perform the exercises every day of the week ${ }^{15-19}$. Considering that the goal is strength gain and body skeletal muscle function improvement, it is recommended to start training with a frequency of two to three days in the week, with a subsequent increase of four to five days, when the level of training is more advanced ${ }^{20}$.

The literature shows the importance of some type of periodization in strength training in the case of skeletal body musculature. Periodization is defined as the division of total training time into specific periods, in order to obtain the highest sporting performance at any given moment ${ }^{11}$. Researches consider that periodized strength training programs result in greater strength gains than non-periodized programs, regardless of the use of single or multiple sets of exercises ${ }^{21,22}$. In addition, the speech therapist's concern with the series of exercises also rests on the possibility of the patient presenting muscle fatigue.

Muscle fatigue can be defined as the reduction, induced by exercise, of the neuromuscular system's ability to generate strength, work or power ${ }^{23,24}$. Its installation may be related to neurological, metabolic, electrophysiological, mechanical and subjective factors, among others, which interfere in the synchronized functioning between the central nervous system and the peripheral pathways ${ }^{25}$, being considered a mechanism of muscle defense to avoid damaging at organic and cellular levels ${ }^{26}$.

Regarding its importance, a few questions of the data collection instrument aimed to investigate the signs and indicative (characteristic) symptoms of muscular fatigue in the face. Most of the participating speech therapists considered tremor/fibrillation as the main sign of muscle fatigue in the facial region. The literature reports that physiological tremors, not observed with the naked eye, occur due to mechanical and neuronal factors and are amplified under conditions of muscular fatigue ${ }^{27}$. The complaint of fatigue and the observation of the compensatory movements were mentioned by half of the participants, however, it is understood that these complaints can occur when the masticatory muscles are hyperactive, generating overload in the temporomandibular joint (TMJ) and the associated musculature ${ }^{28,29}$. Another symptom reported, with a lower percentage, was orofacial pain.

Pain, as a symptom of muscle fatigue in the facial region, was cited by $47.37 \%$ of the sample. According to the literature, the maintenance of muscular exercises, even with the installation of muscle fatigue, can interfere with the onset of muscular kinds of pain and discomforts, as well as motor performance ${ }^{30}$. Only one participant (2.63\%) considered ATM noise as a sign and symptom of muscular fatigue on the face. Noise can be perceived as crackling or crepitation and its origin is intra-capsular, and is mainly related to muscular hyperactivity, changes in the condyle-disc-fossa relationship, occlusal overload and/or trauma leading to anterior dislocation of the disc, a rather frequent sign in individuals with $\operatorname{TMD}^{31,32}$.

A study carried out with the objective of deepening the knowledge about muscular fatigue of the facial and masticatory muscles, through analysis of the scientific literature, concluded that although there are many studies focused on the study of fatigue, the methodology used is quite diverse, making it difficult to compare results. Some studies consider fatigue as a sign of "something different" in the muscle, even consider fatigue as the inability to maintain contractions $^{33}$. The study of muscle fatigue can contribute to the improvement of the parameters for the adequate choice of therapeutic exercises ${ }^{30}$.

Another important consideration is that, in this study, the signs and symptoms of fatigue would require the respondent to indicate more than one alternative and, therefore, this question was not scored. However, 
when the responses were analyzed, the majority did not indicate all the signs and symptoms related to fatigue, implying the need to expand studies and improve the clinical practice in orofacial motor skills of participating speech therapists.

Finally, regarding the asymmetry of tonus between the hemifaces, the literature reveals that the worst side should be more active than the good, in the ratio of two to one. Just over half of the participants (55.26\%) answered this question, that is, the results are not very optimistic.

In general, the total average score (4.13 - totaling $68.83 \%$ ) can be considered as a good result, taking into account that the scores ranged from one point $(16.66 \%)$ to six points $(100 \%)$ and that all the participants worked specifically with orofacial motricity. Thus, the importance of the professional performance in orofacial motricity with a theoretical basis in the physiology of the exercise, for attendance with better quality, is ratified.

The results of this study can only be considered as indicators for new researches, since the study had limitations regarding the size of the sample, although it was considered a sample calculation for its composition. Other limitations to be mentioned are, firstly, that for the sample to be composed, undergraduate or graduate speech therapists were included in different locations in the country, and not exclusively in the state of Sergipe, making it difficult to analyze, in detail, the academic and pedagogical reformulations necessary for a better professional qualification in the area in the state. Secondly, the number of specialists participating in the study (only four), with a greater number being more desirable, so that, the generalization of the results can be performed, which was impossible to be carried out at the moment.

Therefore, new studies should be carried out considering the aforementioned variables, as well as suggesting the approach of the importance of exercise physiology in Orofacial Motricity in different specific clinical signs and in the construction of protocols with parameters for muscular training in the face.

\section{CONCLUSION}

From the results of this study, it can be concluded that the knowledge of the speech therapist of the studied group about the physiology of exercise in orofacial motricity still lacks greater technical-scientific subsidies regarding the sequence, type of contraction and knowledge of the signs and symptoms of muscle fatigue. In addition, there is also a certain scarcity in the work of tonus in asymmetric hemifaces, evidencing weaknesses to be overcome in the clinic in orofacial motricity, even with the variation of time of contraction and number of series of exercises highlighting satisfactory knowledge in the study sample.

The more research on the physiology of exercise in Orofacial Motricity is performed and made available, the higher the range of compatible instruments to be applied in clinical practice.

\section{REFERENCES}

1. Rahal A. Exercícios utilizados na terapia de motricidade orofacial (quando e por que utilizá-los). In: Marchesan IQ, Justino H, Berretin-Felix G (orgs). Terapia fonoaudiológica em motricidade orofacial. São José dos Campos: Pulso; 2013. p. 43-9.

2. Marchesan IQ. Distúrbios da motricidade orofacial. In: Russo ICP (org). Intervenção fonoaudiológica na terceira idade. Rio de Janeiro: Revinter; 1999. p. 83-100.

3. Berretin-Félix G, Araújo ES. Fisiología de la contracción del músculo esquelético y del ejercicio aplicado a la motricidad orofacial. In: Silva HJ, Cunha DA (orgs). El sistema estomatognático: anatomofisiología y desarrollo. São José dos Campos: Pulso; 2013. p. 103-14.

4. Hunter SK, Brown DA. Músculo: o estabilizador primário e motor do sistema esquelético. In: Neumann DA (ed). Cinesiologia do aparelho musculoesquelético: fundamentos para reabilitação. 2. ed. Rio de Janeiro: Elsevier; 2011. p. 47-76.

5. Assencio-Ferreira VJ. Neuroanatomia e neurofisiologia do movimento. In: Rahal A, Oncins MC. (orgs). Eletromiografia de superfície na terapia miofuncional. São José dos Campos: Pulso; 2014. p. 25-40.

6. Zemlim WR. Princípios de anatomia e fisiologia em fonoaudiologia. 4. ed. Porto Alegre: Artmed; 2000.

7. Pate RP, Durstine JL. Exercise physiology and its role in clinical sports medicine. Southern Medical Journal. 2004;97(9):881-7.

8. Jerry TR, Nelson JK, Silverman SJ. Research methods in physical activity. $6^{\text {th }}$ ed. Champaign: Human Kinetics; 2011.

9. Bianchini EMG. Bases da terapia de motricidade orofacial. In: Marchesan IQ, Justino H, Berretin-Felix G. (orgs). Terapia fonoaudiológica em motricidade 
orofacial. São José dos Campos: Pulso; 2013. p. 4-31.

10. Coutrin GC, Guedes LU, Motta AR. Treinamento muscular na face: a prática dos fonoaudiólogos de Belo Horizonte. Rev Soc Bras Fonoaudiol. 2008;13(2):127-35.

11. Silva-Grigoletto ME, Valverde-Esteve T, Brito CJ, García-Manso JM. Capacidade de repetição da força: efeito das recuperações interséries. Rev Bras Educ Fís Esporte. 2013;27(4):689-705.

12. Bompa TO. Periodização: teoria e prática do treinamento. São Paulo: Phorte; 2002.

13. Schmidtbleicher D. Training for power events. In: Komi PV. (org). Strength and power in sport. London: Blachwell Scientific; 1992. p. 381-95.

14. Diels HJ. New concepts in nonsurgical facial nerve rehabilitation. Adv Otolaryngol Head Neck Surg. 1995;9:289-315.

15. Romão AM, Cabral C, Magni C. Early speech therapy intervention in a patient with facial paralysis after otomastoiditis. Rev. CEFAC. 2015;17(3):996-1003.

16. Almeida LF, Lima MC, Macieira JC, César CPHAR, Baldrighi SEZM. Speech therapy in sclerosis systemic: a case report. Rev. CEFAC. 2016;18(1):273-85.

17. Corrêa CC, Berretin-Felix G. Myofunctional therapy applied to upper airway resistance syndrome: a case report. CoDAS. 2015;27(6):604-9.

18. Miranda VHM, Scarpel RD, Torres ACM, Agra IMG. The effectiveness of speech therapy in patients with facial paralysis after parotidectomy. Rev. CEFAC. 2015;17(3):984-95.

19. Diaferia G, Badke L, Santos-Silva R, Bommarito $S$, Tufik S, Bittencourt L. Effect of speech therapy as an adjunct treatment to continuous positive airway pressure on the quality of life of patients with obstructive sleep apnea. Sleep medicine. 2013;14(7):628-35.

20. Kraemer WJ, Adams K, Cafarelli E, Dudley GA, Dooly $C$, Feigenbaum MS et al. American college of sports medicine. American college of sports medicine position stand. Progression models in resistance training for healthy adults. Med Sci Sports Exerc. 2002;34(2):364-80.

21. Kramer JB, Stone MH, O'bryant HS, Conley MS, Johnson RL, Nieman DC et al. Effects of single vs. multiple sets of weight training: Impact of volume, intensity, and variation. J. strength cond. res. 1997;11(3):143-7.
22. Rhea MR, Phillips WT, Burkett LN, Stone WJ, Ball $\mathrm{SD}$, Alvar BA et al. A comparison of linear and daily undulating periodized programs with equated volume and intensity for local muscular endurance. J. strength cond. res. 2003;17(1):82-7.

23. Ascensão A, Magalhães J, Oliveira J, Duarte JA, Soares J. Fisiologia da fadiga muscular. Delimitação conceptual, modelos de estudo e mecanismos de fadiga de origem central e periférica. Rev. port. ciênc. desporto. 2003;3(1):108-23.

24. Enoka RM, Duchateau J. Muscle fatigue: what, why and how it influences muscle function. J. Physiol. 2008;586(1):11-23.

25. Kumar S. Localized muscle fatigue: a review of three experiments. Braz. j. phys. ther. 2006;10(1):9-28.

26. Santos MG, Dezan VH, Sarraf TA. Bases metabólicas da fadiga muscular aguda. Rev. Bras. Ciên. Mov. 2003;11(1):7-12.

27. Borges V, Ferraz HB. Tremors. Rev Neurocienc. 2006;14(1):43-7.

28. Rodrigues ACY, Berretin G, Jorge JC, Genaro KF. Caracterizaçäo das alteraçöes miofuncinais orais e auditivas em indivíduos com disfunçäo craniomandibular. Pró-fono R. Atual. Cientif. 1998;10(1):51-5.

29. Bianchini EMG. Relações das disfunções da articulação temporomandibular com a articulação da fala. Rev Dental Press Ortodon Ortop Maxilar. 2000;5(1):51-9.

30. Silva BARS, Martinez FG, Pacheco AM, Pacheco I. Efeitos da fadiga muscular induzida por exercícios no tempo de reação muscular dos fibulares em indivíduos sadios. Rev Bras Med Esporte. 2006;12(2):85-9.

31. Viana MD, Lima El, Menezes JN, Olegario NB. Evaluation of signs and symptoms of temporomandibular dysfunction and its relation to cervical posture. Rev. odontol. UNESP. 2015;44(3):125-30.

32. Catão MHCV, Oliveira PS, Costa R, Carneiro VSM. Evaluation of the efficacy of low-level laser therapy (LLLT) in the treatment of temporomandibular disorders: a randomized clinical trial. Rev. CEFAC. 2013;15(6):1601-8.

33. Busanello-Stella AR, Silva AMT, Corrêa E. Research on fatigue in facial and jaw muscles: a review of the literature. Rev. CEFAC. 2014;16(5):1627-38. 